\title{
The Latin America and the Caribbean Consortium on Dementia (LAC-CD): From Networking to Research to Implementation Science
}

\author{
Agustin Ibanez $^{\mathrm{a}, \mathrm{b}, \mathrm{c}, \mathrm{d}, \mathrm{e}, *}$, Mario A. Parra ${ }^{\mathrm{d}, \mathrm{f}}$ and Christopher Butler ${ }^{\mathrm{g}, \mathrm{h}, \mathrm{i}, \mathrm{j}}$ for The Latin America and \\ the Caribbean Consortium on Dementia (LAC-CD) \\ ${ }^{a}$ Global Brain Health Institute (GBHI), University of California San Francisco (UCSF), San Francisco, CA, \\ USA \\ ${ }^{\mathrm{b}}$ Cognitive Neuroscience Center (CNC), Universidad de San Andrés, Buenos Aires, Argentina \\ ${ }^{\mathrm{c}}$ National Scientific and Technical Research Council (CONICET), Buenos Aires, Argentina \\ ${ }^{\mathrm{d}}$ Universidad Autónoma del Caribe, Barranquilla, Barranquilla, Colombia \\ ${ }^{\mathrm{e}}$ Latin American Institute for Brain Health (BrainLat), Center for Social and Cognitive Neuroscience (CSCN), \\ Universidad Adolfo Ibanez, Santiago de Chile, Chile \\ ${ }^{\mathrm{f}}$ School of Psychological Sciences and Health, University of Strathclyde, Glasgow, UK \\ ${ }^{\mathrm{g}}$ Department of Brain Sciences, Imperial College London, UK \\ ${ }^{\mathrm{h}}$ Nuffield Department of Clinical Neurosciences, University of Oxford, Oxford, UK \\ ${ }^{\mathrm{i}}$ Instituto de Neurología Cognitiva, Buenos Aires, Argentina \\ ${ }^{\mathrm{j}}$ Departamento de Neurología, Pontificia Universidad de Chile, Santiago, Chile
}

Accepted 3 December 2020

Pre-press 21 January 2021

\begin{abstract}
In comparison with other regions, dementia prevalence in Latin America is growing rapidly, along with the consequent clinical, social, and economic burden upon patients and their families. The combination of fragile health care systems, large social inequalities, and isolated clinical and research initiatives makes the coordination of efforts imperative. The Latin America and the Caribbean Consortium on Dementia (LAC-CD) is a regional organization overseeing and promoting clinical and research activities on dementia. Here, we first provide an overview of the consortium, highlighting the antecedents and current mission. Then, we present the consortium's regional research, including the multi-partner consortium to expand dementia research in Latin America (ReDLat), which aims to identify the unique genetic, social, and economic factors that drive Alzheimer's and frontotemporal dementia presentation in LAC relative to the US. We describe an extension of ReDLat which aims to develop affordable markers of disease subtype and severity using high density EEG. We introduce current initiatives promoting regional diagnosis, visibility, and capacity, including the forthcoming launch of the Latin American Brain Health Institute (BrainLat). We discuss LAC-CD-led advances in brain health diplomacy, including an assessment of responses to the impact of COVID-19 on people with dementia and examining the knowledge of public policies among experts in the region. Finally, we present the current knowledge-to-action framework, which paves the way for a future regional action plan. Coordinated actions are crucial to forging strong regional bonds, supporting the implementation of regional dementia plans, improving health systems, and expanding research collaborations across Latin America.
\end{abstract}

\footnotetext{
*Correspondence to: Agustin Ibanez, Cognitive Neuroscience Center (CNC), Vito Dumas 284, B1644BID, Buenos Aires,
}

Argentina. Tel.:+54 91130279893; E-mail: agustin.ibanez@gbhi. org. 
Keywords: Dementia, genetics, implementation science, LAC-CD, Latin America, neurodegeneration, neuroimaging, regional health, social determinants of health, socioeconomic status

\section{DEMENTIA IN LATIN AMERICA}

Latin America and the Caribbean countries (LACs) constitute a region of immense beauty, variety, and culture. However, the region also faces enormous health and societal challenges. Among these, neurodegenerative diseases pose perhaps one of the most daunting. While dementia has been declared a global health priority [1-7], the perils are particularly acute for LACs [1, 2, 8-11]. The demographic structure of LACs is rapidly approaching that of developed countries, and it is predicted that the prevalence of dementia in the region will exceed the global estimates, with a projected increase of between $77 \%$ to $146 \%$ [12, 13]. Although globally around $35-40 \%$ of dementia cases can be explained by known risk factors [14], in LACs this proportion escalates to 56\% [15], being the largest across the reported regions (Fig. 1). Barriers to adequate dementia care across LAC arise from low levels of awareness among professionals and the general public, limited resources for training, inadequate diagnostic facilities, stigma, language barriers, low socioeconomic and educational levels, and poor access to basic health and social care $[2,16$, 17]. These challenges are accentuated by key gaps in knowledge and infrastructure: 1) limited reliable epidemiological data, 2) lack of a regional strategy promoting dementia-specific health policies and budgets, 3) absence of culturally valid, systematic dementia assessment procedures, 4) lack of a unified agenda across LACs to facilitate collaboration and rapid translation of research outputs. These complex horizontal challenges cannot be tackled via simple vertical efforts. A horizontal approach which captures and integrates the main challenges, relevant coordination between actors, and priority-based timelines, will be critical features underpinning a regional dementia strategy. That is precisely the aim of the recently proposed LAC-CD Knowledge-to-Action Framework (KtA, see below). Via six synchronized agendas, the newly proposed KtA will address gaps in the areas of biomarkers, genetics and epidemiology workgroups, data platforms, clinical trials, non-pharmacological interventions, and translational research. These areas have been identified as priorities by LAC-CD and its associated partners (e.g., Alzheimer's Association, Global Brain Health Institute).

\section{The mission of the Latin America and the} Caribbean Consortium on Dementia (LAC-CD)

Motivated by this wide range of dementia-related challenges, the LAC-CD is regional organization overseeing and promoting clinical and research activities in dementia. LAC-CD is aimed to 1) train a new generation of health professionals, 2) support multicentric research and clinical practice via networking, 3) develop protocol harmonization for clinical assessments, 4) validate such assessment in unique populations, 5) amplify the support from regional and international grant proposals emerging from LAC networks, 6) support evidence-based decisions with fast-track access to knowledge, and 7) set up efficient communication channels between researchers, clinicians, governments and private agencies to promote national and regional dementia strategies.

\section{The history of LAC-CD}

In 2015, a small group of colleagues met in Santiago, Chile, during the XXII World Congress of Neurology, to discuss how dementia research in LACs could be better integrated (Fig. 2). Insights gained at this meeting became the building blocks of an Opinion paper [2] which identified the key challenges facing the region and proposed a number of action points.

A second summit with 40 experts at the Alzheimer's Association International Conference (AAIC in London, 2017) developed further actions toward regional integration. In 2018, a larger group met at an AAIC Satellite Symposium in Buenos Aires. At this stage, the Inter-American Development Bank provided support for a 3-year project (Behavioral Insight Group for social protection and health policies: A lifespan approach) to realize the group's initiatives toward the development of regional diagnostic manuals and a regional data platform for dementia. An online survey among LAC-CD members helped distinguish key priorities for future action (Fig. 3).

The AAIC 2019 Satellite Symposium in Sao Paulo, Brazil hosted the official launch of LAC-CD, and LAC-CD national representatives were appointed. Topics discussed at this meeting included the need 


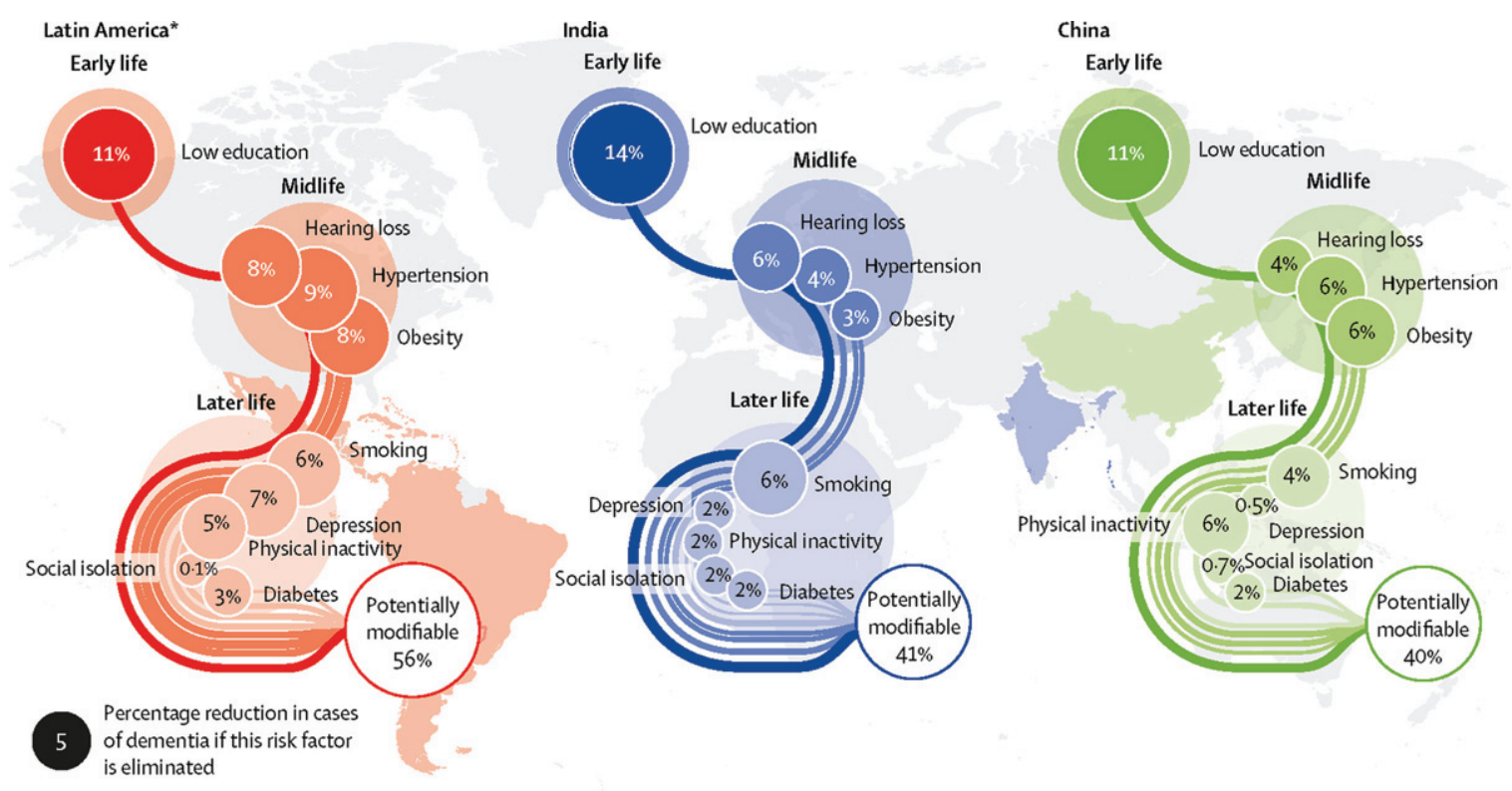

Fig. 1. Population attributable fractions for potentially modifiable risk factors in low-income and middle-income countries. Data for Latin America include the data for Cuba, Dominican Republic, Mexico, Peru, Puerto Rico, and Venezuela. Reproduced with permission from [15].

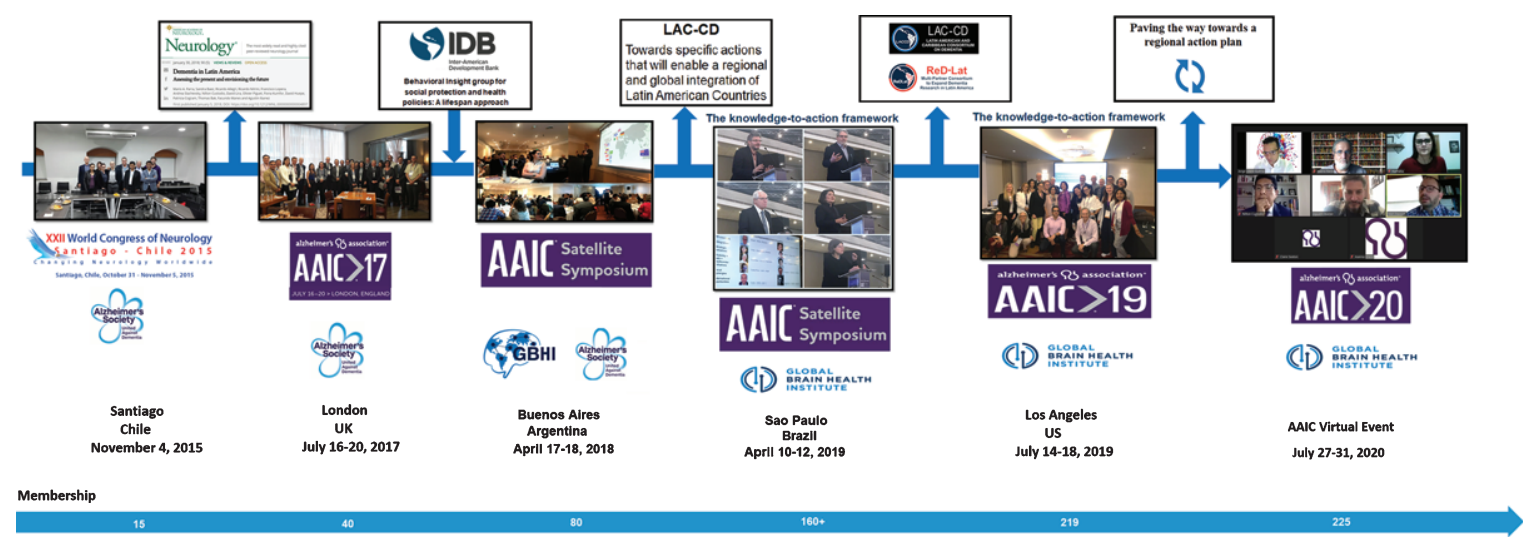

Fig. 2. The LAC-CD timeline illustrates the growth of the consortium over the last five years. The consortium membership, regional representativeness, and its appeal to international organizations (i.e., GBHI, Alzheimer's Association) have all grown steadily from its outset. Its evidence-based agenda started by characterizing challenges and opportunities in the region. Such knowledge has supported successful large grant applications and has informed a new action framework that aims to transform the dementia landscape in LAC. Modified and reproduced with permission from [1].

for a Knowledge to Action Framework that would guide future steps; fundraising for future meetings; the contents of a regional manual to support diagnosis; a review of training and funding opportunities; strategies for dissemination and monitoring the goals of the LAC-CD; and synergies with the Alzheimer's Association and Global Brain Health Institution (GBHI). The LAC-CD met again during the AAIC 2019 held in Los Angeles, USA. The agenda for the Knowledge-to-Action Framework was presented (and later published in [1]). Country representatives proposed specific bottom-up initiatives to enable LAC integration via existing or new projects. LAC-CD also discussed strategies to attract new partners/members from leading organizations and to form a training agenda for representatives and interested members. The last convention was hosted at the AAIC 2020 Virtual Meeting and included a discussion of LAC-CD highlights and achievements; a focus on adaptive transformations for research, care and 

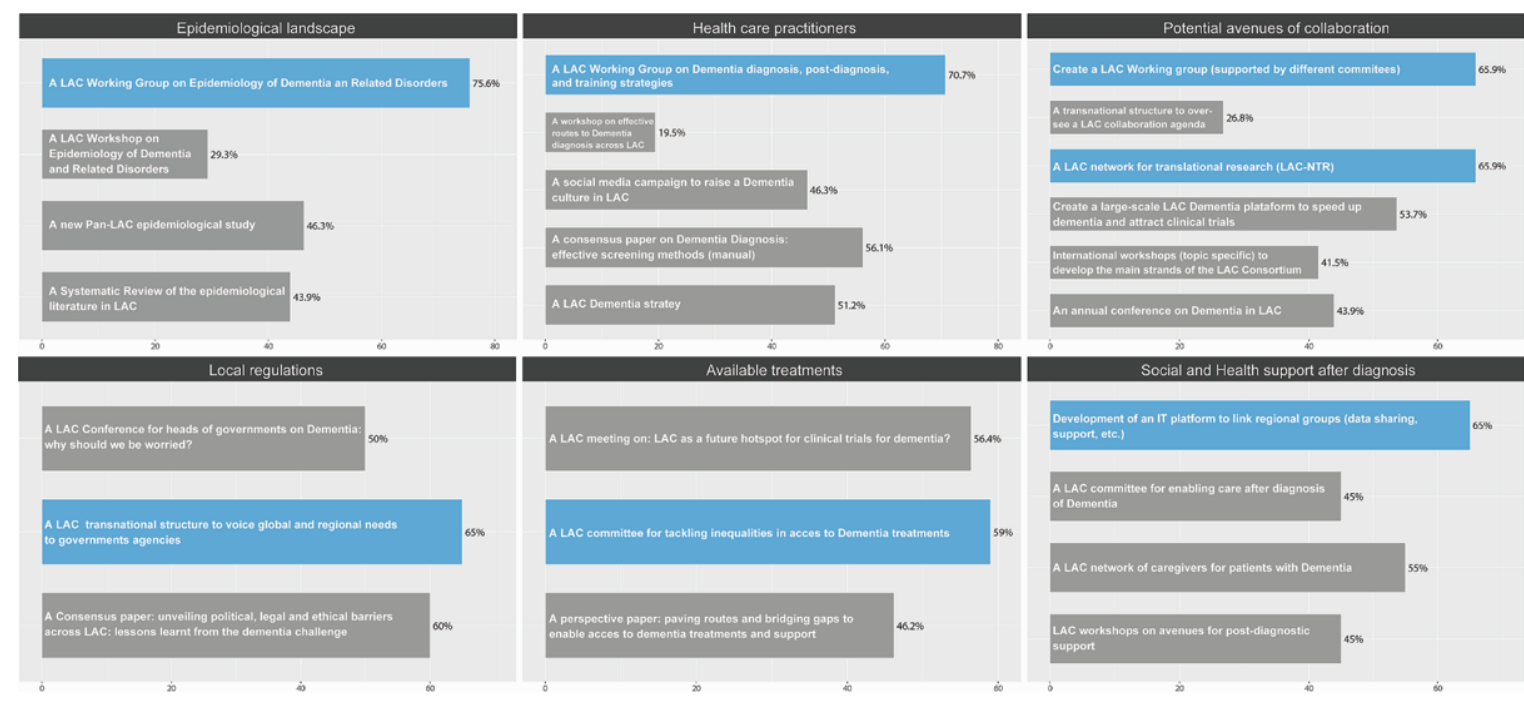

Fig. 3. Outcomes from an online survey completed by members of the LAC-CD ( $N=230$ experts). Members voted on specific actions to fulfill the objectives set by six topics: epidemiological landscape, health-care practitioners and dementia diagnosis, potential avenues for collaboration, local regulations, currently available treatments and views on social and health support after diagnosis. The members were able to select more than one option per topic and suggest other actions. Values show the percentage of voters endorsing each action. Blue indicates the option attracting the highest proportion of votes under each topic. LACs, Latin American and Caribbean countries; IT, information technology; LAC-NTR, LAC Network for Translational Research. Reproduced with permission from [1].

health systems regarding the COVID-19 pandemic; research reports of different studies running in LAC; and LAC-CD connection with other global Initiatives and with the Africa Dementia Consortium (ADC).

To date, the consortium has involved more than 240 regional leaders and members from LACs and is now supported by the Alzheimer's Association and the GBHI. National representatives help orientate the LAC-CD framework toward identified priority areas including dementia biomarkers, genetics and epidemiology, a dementia data platform, a clinical trial program, nonpharmacological interventions, and translational research networks. These national representatives also ensure that the framework remains comprehensive, integrative, and harmonized, helping to transform identified barriers into unprecedented opportunities for LACs.

\section{MULTICENTER AND MULTIMODAL RESEARCH: REDLAT}

The LAC-CD, together with investigators from the USA and Europe, developed a research agenda to tackle the unique combination of genetic and socioeconomic status and social determinants of health (SES/SDH) risks for dementia in LACs [1]. The current active research agenda in LAC includes basic animal studies [18], as well as genetic (see a review: [19]), clinical (see a review: [1]), neurocognitive (e.g., [20-38]), biomarker (see a review: [1]), and caregiver-center research (e.g., [39-46]) across neurodegenerative conditions. These examples illustrate the enormous research potential of LAC which, despite funding and infrastructure constraints, is contributing valuable knowledge particularly by advancing and integrating regional and global initiatives. Nevertheless, this potential is still emergent and remains under-realized. The integrated efforts our agendas bring together are aimed at realizing it further, making it both more representative and more globally visible.

The multi-partner consortium to expand dementia research in Latin America (https://www.gbhi.org/ projects/multi-partner-consortium-expand-dementia -research-latin-america-redlat; ReDLat, supported by the NIH-NIA, the Alzheimer's Association, the Rainwater Charitable Foundation or Tau Consortium, and the GBHI) is an ongoing international initiative aimed at recruiting participants with $\mathrm{AD}$, frontotemporal dementia (FTD), and controls from 10 sites in Argentina, Brazil, Chile, Colombia, Mexico, Peru, and the US ( $>4,200$ participants, 2,100 controls, 1,050 AD patients, and 1,050 FTD patients). RedLat long-term goal (Fig. 4) is to identify the unique genetic and SES/SDH factors that drive AD and FTD 


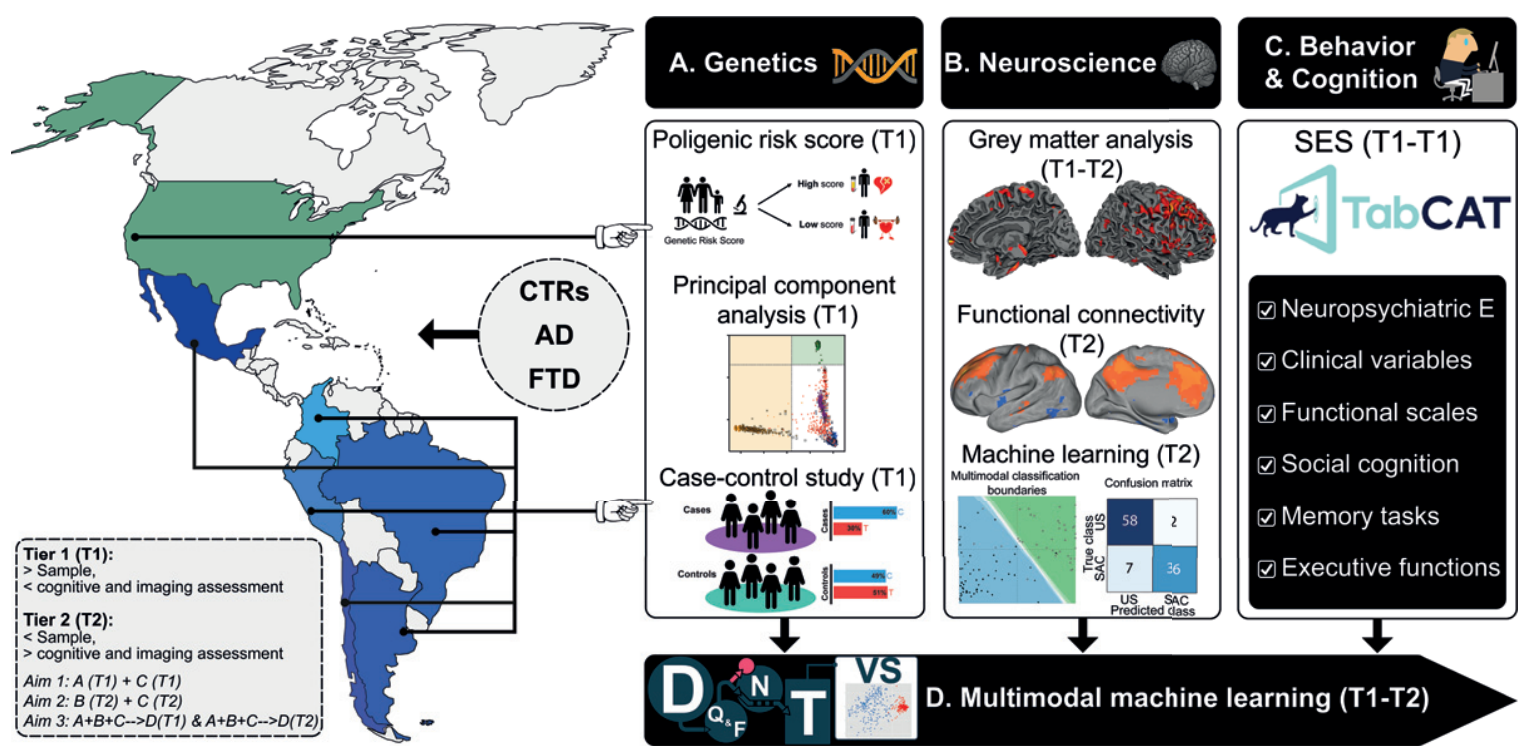

Fig. 4. The ReDLat initiative. Systematic comparisons between LAC and US samples of AD and FTD via a novel, multimodal approach. The multimodal patterns will be assessed with different measures of (A) genetic risk (Aim 1), (B) imaging markers boosted by computational approaches, and (C) harmonized and novel measures of cognitive profiles and SES/SDH (Aim 2). These data sources will be (D) integrated and compared across countries through machine learning (Aim 3) to unveil the main commonalities and differences between US and LAC samples. Tier 1 (T1): Larger study (Aim 1 \&3). Tier 2 (T2, smaller study with deep neurocognitive investigation (Aim 2 \& 3). D, data; Q\&F, quality \& feature extraction; N, normalization; T, test; VS, visualization.

presentation in LAC relative to the US, including risk factors, cognitive profiles, and brain imaging. The ReDLat specific aims include: 1) the identification of genetic contributions to AD and FTD across LAC cohorts, including causative genes and polygenic risk score (PRS); 2) determining the impact of SDH in the multimodal presentation of dementia (clinical, cognitive, and multimodal neuroimaging); and 3) combining, via machine learning, multi-feature genetic and SDH risks to discriminate between LAC and US patients as compared with other cognitive, neuroimaging, and clinical variables. By combining standardized genetic, neuroimaging, and behavioral (cognitive and SES/SDH) measures and machine learning, ReDLat will be able to predict the genetic and SES/SDH risk factors for AD and FTD in LAC in comparison to the US.

\section{MULTICENTRIC AND MULTIMODAL RESEARCH: EEG}

While LAC-CD acknowledge that projects such as ReDLat will have a transformative impact on our understanding of dementia phenotypes and genotypes in the region, it is also aware that diagnostic and disease characterization solutions to inform such phenotypes are unlikely to be widely available in the region any time soon. To bridge these gaps, the consortium have proposed strategies such as the investigation of affordable diagnostic solutions, i.e., the EEG.

The assessment of high-density EEG research has emerged as a highly promising method to establish both transdiagnostic and disease-specific markers for dementia [47-49]. EEG brings non-invasive, affordable, non-fatiguing measures supporting early deficit identification and complementary neurophysiological biomarkers across diseases. The LAC team has strong expertise in EEG markers, which offers different sets of measures including eventrelated potentials, oscillations, connectivity measures, source space analysis, decoding and machine learning approaches, for both active tasks and resting state recordings [28, 29, 33, 50-83] alone or in combination with other technics [28, 50, 76, 77, 84-88]. In a regional project based on ReDLat platform and supported by Takeda, we will establish the sensitivity of multimodal EEG markers vis-à-vis cognitive (standardized coarse-grained cognitive tests), and neuroimaging ones (i.e., structural MRI, functional connectivity derived from fMRI) for discriminating among neurodegenerative disease subtypes (AD versus FTD), status (familial versus sporadic), 
and predicting disease progression from the ReDLat protocol. We will implement a multi-feature machine learning framework via a novel multimodal electrophysiological markers (derived from EEG) neuroimaging pipeline (high density EEG, MRI, and fMRI) and a set of sensitive behavioral (cognitive) measures. With these multicultural samples, we will be able to test the underlying hypothesis that, in discriminating among patients and tracking disease severity and familial status, potential EEG markers will prove at least as sensitive as cognitive and neuroimaging markers, irrespective of the patients' SES/SDH. Moreover, we will examine the prediction that overall prediction of disease subtype, status, and severity, based on clinical, imaging, and cognitive data, will be boosted by the inclusion of EEG markers. In testing both hypotheses, multimodal measures from controls will be used for disease-specific normalization of patient data and between-group comparisons. Furthermore, the use of data-driven machine-learning analysis will offer a cutting-edge platform to tackle the many sources of heterogeneity across culturally diverse samples. Crucially, results will be contrasted, validated, and harmonized against multicenter databases. This project will add a dimension to the RedLat multimodal brain imaging goal to compare the multi-feature and multilevel markers of dementia. In particular, the connectivity fluctuations already identified in dementia with neuroimaging [89] will be assessed at a higher temporal resolution by incorporating and further developing EEG-based methodologies.

LAC-CD has recently proposed a knowledge to action framework which comprises a biomaker agenda (i.e., LAC-BF) [1]. This agenda will partialy rely on the UK-Latin America Brain Connectivity Research Network (UL-BCRN; http://laccd.org/en/proyects/) to support regional validation of low-cost, easy to access EEG-based biomarkers againts those recommended by the current NIA-AA framework [90]. The UL-BCRN is an initiative that aims to advance and support research into the development of EEG biomarkers for dementia. It was launched in 2013 by Parra and Ibanez [91] with the support from the MRC UK as part of a collaboration between the Human Cognitve Neurscience Group of the University of Edinburgh and the Institute of Cognitive Neurology of Buenos Aires. The UL-BCRN aims to connect researchers and laboratories around the globe who share an interest in the EEG as a diagnostic tool for dementia. The EEG as an affordable and reliable diagnostic tool has gained momentum over the last few years [47-49]. These solutions will have the greatest impact on LAC as the biomarkers recommended by the NIA-AA framework will not be widely available in the region any time soon. The UL-BCRN curently links labs across the UK, Colombia, Argentina, Peru, Chile, and Brazil. It has already contributed evidence supporting the regional impact of the network.

\section{REGIONAL DIAGNOSIS, VISIBILITY, AND CAPACITY BUILDING}

A key goal of LAC-CD is to develop a regional, harmonized approach to dementia diagnosis in order to allow multi-country comparisons. We initially developed diagnostic recommendations [92], including relevant clinical, neuropsychological, and behavioral measures, for the identification and diagnosis of $\mathrm{AD}$ and FTD in Latin American individuals. We focused on specific aspects that would facilitate adequate diagnosis in settings where the resources needed for accurate classification of dementia syndromes are not always available. Carrying this concept further, we have collaborated with the Inter-American Developmental Bank (IDB) to develop a manual for dementia diagnosis (http://lac-cd.org/en/2020/06/17/manualfor-best-practices-for-the-dementia-diagnosis/). The manual was highlighted in multiple media, as well as by the Alzheimer's \& Dementia journal [93]. The content of this manual is based on results of a survey of regional experts, with oversight from a panel of international leaders, including clinicians and researchers from UCSF and GBHI. The manual includes five sections (Dementia in Latin-American; Epidemiology and health system in the region, Clinical assessment of dementia; Neuropsychological assessment, Carers).

In order to amplify the visibility and disseminate the consortium activities, a LAC-CD website (http://lac-cd.org/) is now available in English, Spanish, and Portuguese. The website includes information about the history, projects, membership, and contact information of LAC-CD; several dissemination products, including videos from LAC-members and UNICEF about dementia; press releases and regular social media updates. Together with the Alzheimer's Association, we have developed a series of LAC-CD-ISTAART webinars including an annual meeting (July 2020), a webinar focused on phenotyping dementia and biomarkers (September 2020), and a third on brain health/cognitive screening and 
clinical trials (September 2020). From 2021, LACCD will host periodic ISTAART webinars.

Supported by LAC-CD, a new Latin American Institute for Brain Health (BrainLat) will be launched in Chile on 2021, hosted by the University Adolfo Ibanez (UAI). BrainLat will bring together leading national and international institutions in brain science, including the UAI (School of Psychology, Faculty of Engineering and Science, Schools of Government and Business), and two public institutions (the Geroscience Center (GERO) and the Memory and Neuropsychiatry Clinic of the University of Chile, CMYN). BrainLat is affiliated with the GBHI at UCSF in order to develop several actions, including shared affiliations, joint training programs, mobility and faculty interaction as well as research networking and conjoint applications. Supported by this network, the institute will conduct world-class interdisciplinary and translational research in brain health, train new researchers, and disseminate evidence to broad audiences expanding the LAC-CD efforts and providing capacity building. BrainLat brings direct initial funding of US\$ 4.7 million for the first five years, plus infrastructure support, a $\mathrm{PhD}$ program, neuroscientific equipment, and permanent support for 16 full research positions.

\section{BRAIN HEALTH DIPLOMACY AND REGIONAL COORDINATED EFFORTS}

Despite the significant and growing challenges posed by dementia, no multilateral, coordinated response exists for LACs [1, 94]. Brain health diplomacy (BHD) and convergence science [95-97] can provide a framework for the development of such responses based on the integration of tools, knowledge, institutions, and strategies developed at different interfaces. BHD is a "model to transcend disciplinary boundaries, and mobilize resources at sufficient scale to improve brain health. This model builds on several theoretical approaches, including health diplomacy, science diplomacy, innovation diplomacy, and convergence science" ([95], p. 973). In comparison with classical approaches, BHD can better coordinate interdisciplinary and multisectoral global calls to develop systematic actions in the face of complex health issues. BHD can integrate LAC governments and non-governmental organizations (NGOs) to develop innovative solutions with telemedicine, artificial intelligence, patient monitoring, and coordinated actions at individual, community, and regional levels with global policy.
BHD has been important in promoting a range of LAC-CD calls for action and coordinated responses to regional challenges. For instance, we recently raised awareness of the long-term syndemic impact of SARS-CoV-2 upon people with cognitive decline or dementia in LACs (Fig. 5), as well as their families and the research and public health systems [94]. More recently, collaborators from LAC-CD have proposed a collaborative response to anticipate the upcoming challenges [98]. This includes (a) general recommendations: coordination and integration of preventative measures, sound epidemiology, dissemination of practical knowledge, and promotion of risk awareness and (b) specific recommendations including massive testing for dementia populations (point-of-service testing based on scalable technologies with low-cost instrumentation, non-specialized training and available reagent supply chain) and boosting regional coordination (e.g., between available standards such as the OECD Policy Response to COVID-19 or the G20's large-scale coordination and regional NGOs; between interregional agencies and multicentric research). We advise that multiregional NGOs focused on dementia (Alzheimer's Association, Alzheimer's Disease International, the GBHI), should partner with local institutions to coordinate a leadership action plan to mitigate the impact of COVID-19 on people with dementia and their carers in LACs.

BHD also promotes the development of shared regional expert knowledge on brain health [95-97]. Health professionals working in aging are critical agents to promote diagnosis, care, and research in dementia. In a recent study [99], we investigated multiple dimensions of expert knowledge of health professionals in LACs $(\mathrm{N}=3,365)$ with regression models including expertise-related information (public policies, BI), individual differences (work, age, academic degree), and location. Results reveal a strong knowledge gap about dementia which has a negative impact at multiple levels (Fig. 6) including access and transmission of public health knowledge and stigma among professionals. They demonstrate the urgent need for regional manuals for best practices and platforms for sharing clinical and research data. They furthermore clearly indicate specify actions that should be taken by governmental agencies and NGOs to improve dementia knowledge in LACs.

These coordinated strategies should provide support to governmental institutions in every country. For instance, countries without ongoing regional plans can collaborate via BHD with those with consolidated 

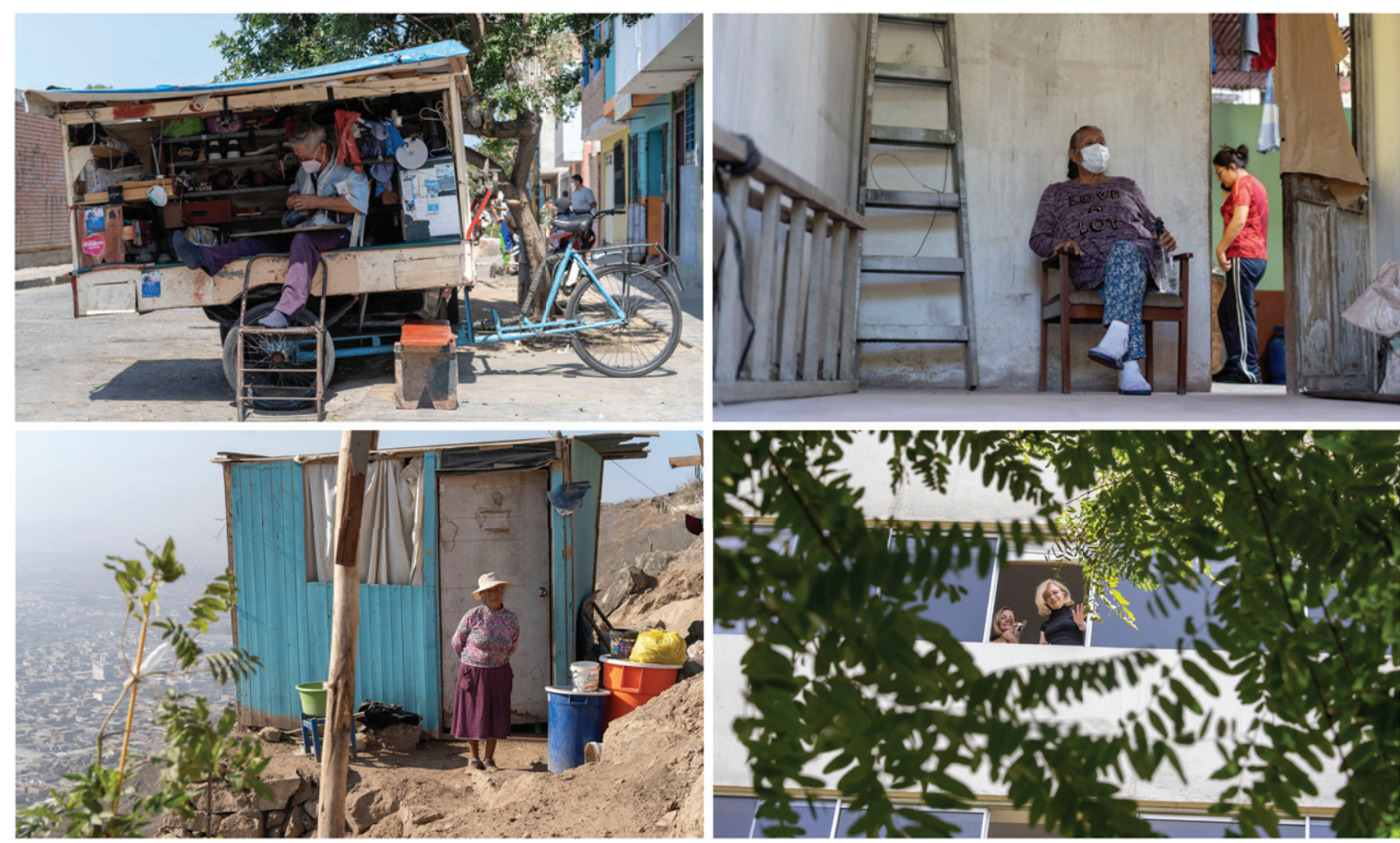

Fig. 5. Testimonies from Peru highlighting different dimensions of the coronavirus outbreak and their impact on older people, and patients with cognitive decline and their families. The pictures above illustrate the people's vulnerabilities and the unpreparedness of the health system. Top left inset: Enrique (64 years old, Trujillo) suffers from diabetes mellitus but has been unable to get medication for two months. $\mathrm{He}$ is a shoe repairer with a small mobile stall and, after months of quarantine, he has to go out to work. Top right inset: Juana (64 years old, Trujillo) is a merchant diagnosed with coronavirus three months ago, which led to her needing supplemental oxygen and intravenous medications. Given the collapse of the hospitals, she was treated at home by her daughter. She thought she might lose her life, unable to perform simple activities (such as walking and eating) without great effort. Now she is recovering. Bottom left inset: Enedina (65 years old, Lima) lives with her youngest son who lost his job due to the pandemic restrictions. They live in a precarious room, without electricity, water or drainage. Bottom right Inset: On the other side of Lima, 83-year-old Mrs. Rosita lives with her family in a wealthy district. Her daughter has noted typical dementia symptoms, which have exacerbated since the quarantine. She doesn't understand the isolation, needs constant monitoring and urgently requires a neurological evaluation, but there are no services available due to the pandemic. Photos and testimonies from Peru documented by Alexander Kornhuber and Maritza Pintado Caipa. Individuals and relatives portrayed in the photos have provided written consent for reproduction. Reproduced with authorization from [98].

regional plans. Sharing of specific knowledge, effective strategies and coordinated actions across countries can expedite the emergence and effectiveness of new national action plans.

\section{TOWARDS A REGIONAL ACTION PLAN}

LAC-CD has proposed a Knowledge to Action Framework (KtAF) to develop a future dementia regional action plan [1]. The KtAF will help translate the multi-domain research-based knowledge into practical tools pertinent for different stakeholders, including policymakers, clinicians, patients, families and researchers. The Knowledge creation provides a basic stage to develop focused actions. Through several cycles which involve the abovementioned stakeholders, the knowledge base will be expanded and the ensuing actions refined. The KtAF can thus provide the tool to integrate challenges, knowledge, and actions following a coordinated horizontal plan.

Current dementia diagnosis among patients with low education is proving challenging [100-102]. Low education also increases the burden for caregivers [39] including Argentina [40], Brazil [41], Chile [42], Colombia [43], Mexico [44], Peru [45], and Uruguay [46] and widens the disparity gaps we have long witnessed across the region (e.g., limitations for people living in rural areas and members of indigenous communities). Careful analysis is required of how these conditions contribute to the challenges faced by LAC in dealing with dementia. Through such work, we envisage that barriers can be turned into opportunities and access to diagnosis, treatments (e.g., clinical trials and other interventions) and support will improve. 
| Accessibility
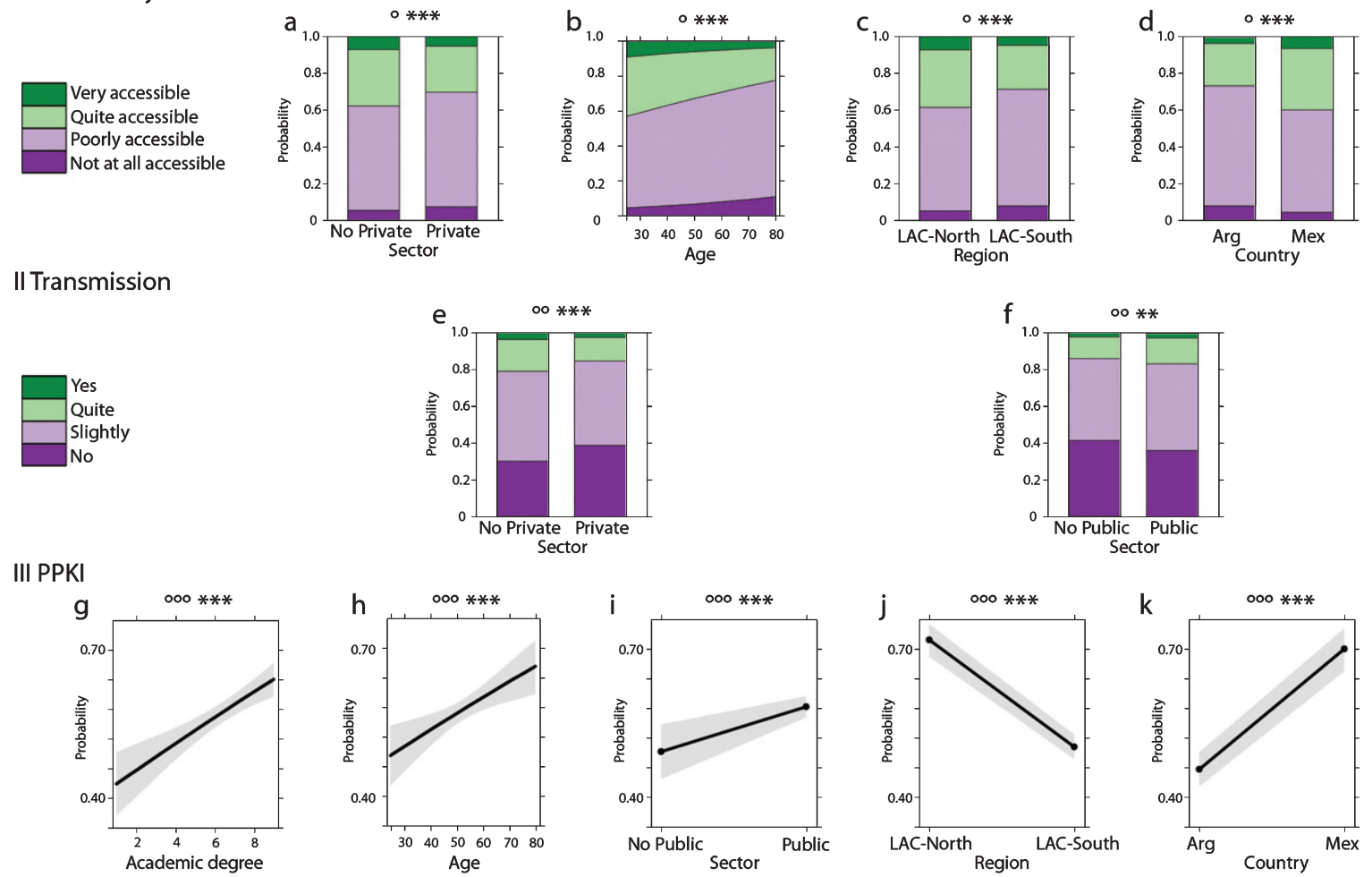

\section{Dementia}
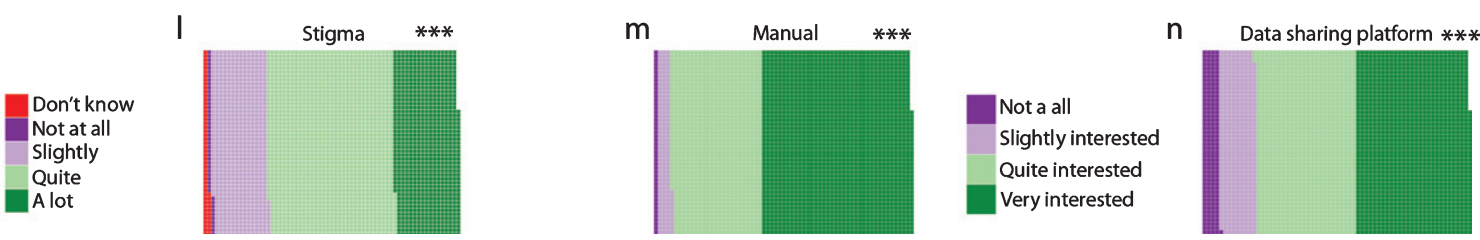

Fig. 6. Dementia public policies in Latin America. I. Public Policies Accessibility. A) Probability of response frequency regarding accessibility by sector. B) Probability of response frequency regarding accessibility by age. C) Probability of response frequency regarding accessibility by region. D) Interaction of probability of response frequency of accessibility by country. II. Public Policies Transmission. E) Probability of response frequency regarding transmission by private sector. F) Probability of response frequency regarding transmission by the public sector. III. PPKI (Public Policy Knowledge Index). G) Probability of response frequency regarding high PPKI by academic degree. H) Probability of response frequency regarding high PPKI index by age. I) Probability of response frequency regarding high PPKI by the public sector. J) Probability of response frequency regarding PPKI by public region. K) Probability of response frequency regarding PPKI by country. IV. Aging. L) Proportion of responses about aging stigma. M) Proportion of responses about interest in aging and dementia manual. N) Proportion of responses about interest in a data-sharing platform. Significance (p values): effects significance $\left({ }^{*} p \leq 0.1,{ }^{* *} p \leq 0.05,{ }^{* * *} p \leq 0.01\right.$ ), model significance $\left({ }^{\circ} p \leq 0.1,{ }^{\circ} p \leq 0.05,{ }^{\circ 00} p \leq 0.01\right)$. Academic degree: 1 : No reported education, 2: Technicians, 3: Tertiaries, 4; Certificates, 5: Undergrads, 6: Hospital Interns, 7: Post-graduate Specialization, 8: Master's Degree, 9: Ph.D. Reproduced with authorization from [99].

Such knowledge will also support the revision of local ethical regulations, which still need to overcome issues relating to equity and disparity.

We have first identified common priority areas across the region (Fig. 7) including: 1) Risk factors for dementia and non-pharmacological interventions, 2) Epidemiological and genetic studies, 3) Biomarkers for dementia, 4) Clinical trials, and 5) Networking and translational research. We have identified evidence-based strategies to tackle the main challenges taking into account key sources of complexity (genetic isolates, admixture in populations, environmental factors, and barriers to effective interventions), mapped them to the above priorities, and provided the basic mosaics of knowledge towards a KtAF. Such processes of knowledge synthesis have been endorsed by experts as means of developing third-generation knowledge [103].

Specific challenges will be tackled by distinct workgroups within the KtAF (Fig. 8). The Non- 
Ranking of priority areas and related challenges in the short and long term

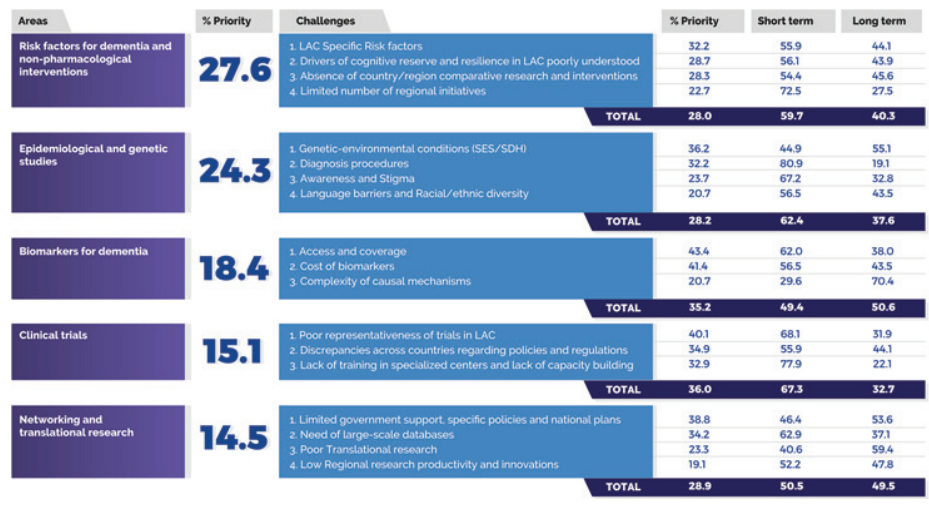

Timeline for the Action Plan

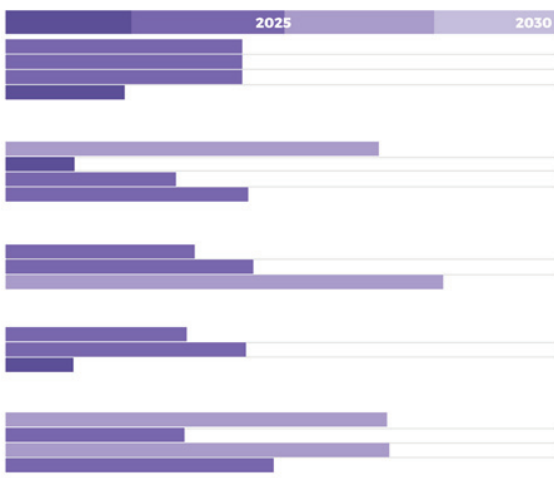

Fig. 7. Priority levels assigned to core areas and challenges via a knowledge inquiry and related actions timelines. LAC-CD regional experts $(\mathrm{N}=220)$ were presented with a survey and were asked to rank the 5 areas and associated challenges in order of priority. We calculated the percentage of respondents who rated these within the top two priorities and used these to rank both areas and challenges. The right inset shows the timeline for the proposed actions. Experts were also asked to deliver their views about a feasible timeline to address these challenges and actions (0-5 or 5-10 years) (\%= Mean \% of responses). Reproduced with authorization from [1].

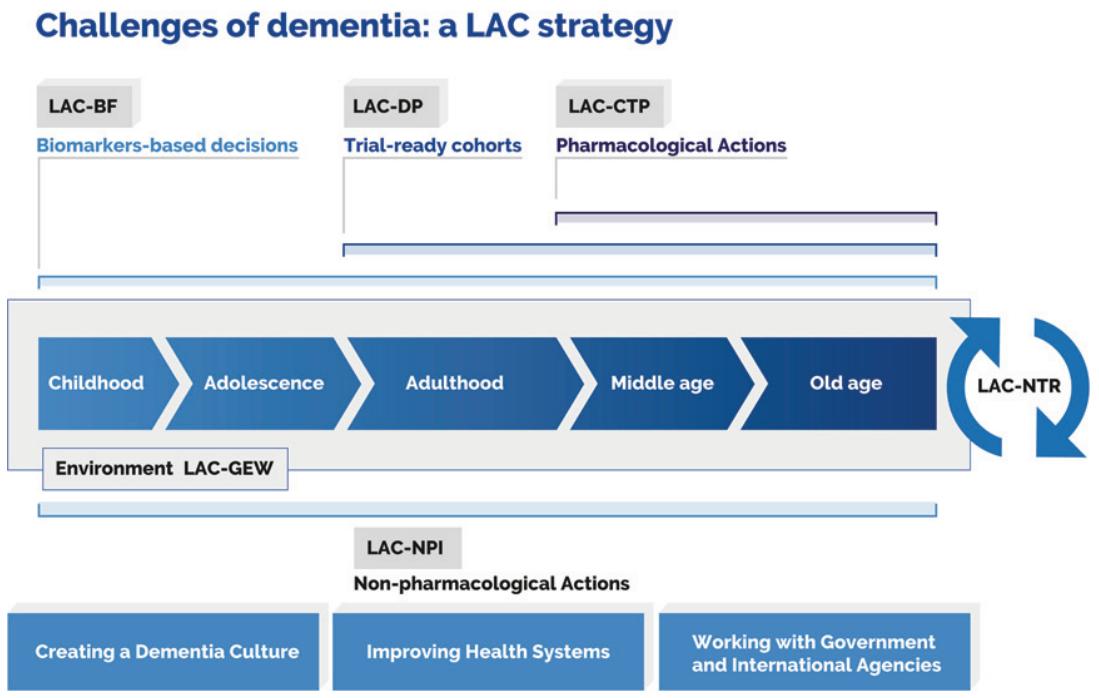

Fig. 8. Knowledge-to-action framework. The diagram captures challenges posed by dementia and the related mapping of key actions. Such actions may be linked to specific working groups that have been included in the framework. This approach comprises a biomarker framework (LAC-BF), genetics and epidemiology workgroup (LAC-GEW), dementia platform (LAC-DP), clinical trial program (LAC-CTP), nonpharmacological interventions (LAC-NPI), and an LAC network for translational research (LAC-NTR). Reproduced with authorization from [1].

pharmacological Interventions Workgroup (LACNPI) will address LAC specific risk factors by connecting with international initiatives; strengthening surveillance capacity by incorporating the World Health Organization (WHO) STEPwise approach; promoting National Dementia Plans in the region; developing research on cognitive reserve and resilience and improving training and educational programs via the GBHI and the Alzheimer's Association. The Genetic and Epidemiology Work- group (LAC-GEW) will focus on implementation of pan-LAC epidemiological studies; identification of specific lifelong factors affecting neurocognitive development; expansion of family history and genetic protocols such as those developed by the Neuroscience Group of Antioquia, Colombia; development of a digital platform for data sharing following harmonized procedures; increasing research on genetic heterogeneity; and promoting the establishment a LAC dementia observatory. The Biomarker 
Framework (LAC-BF) aims to develop alternative affordable biomarkers based on cognitive assessment, eye-tracking, noninvasive peripheral markers (i.e., plasma markers.), and multimodal neuroimaging (e.g., EEG, MRI, fMRI, DTI), combined with machine- and deep-learning algorithms [20, 21, 24-27, 31, 88, 89, 104, 105]; validating such potential biomarkers against the A/T/N framework [90]. The Clinical Trial Program (LAC-CTP) will identify main countries and hubs with the required infrastructure to develop prevention trials; connect trial programs with national regulatory agencies to harmonize regional policies; promote the development of trial-ready cohorts across different countries; and launch a clinical trial training program from expert centers to other less experienced centers. Finally, the Network for Translational Research (LAC-NTR) will promote translational research through a network of scientists, clinicians, pharmaceutical leaders, and government representatives; develop digital platforms to amplify collaboration and resource sharing; and promote synergy among different regional initiatives. These key KtA avenues will work together to fight dementia in the region by increasing awareness, knowledge, and resources in an equitable way.

\section{CONCLUSIONS AND FURTHER ADVANCES}

LAC-CD is an emergent, multimodal taskforce promoting research, networking, capacity building, and implementation science for dementia in LACs. We envisage that the consortium will be further integrated with other NGOs and research initiatives in the region. Such integration will be crucial to promote a strong bonding at a regional level, maximize the implementation of regional dementia plans, liaise with government representatives, improve health systems across the region, and expand the networking and translational initiatives developed by LAC-CD.

Neuroscientists across Latin America represent a powerful taskforce for developing translational and impactful dementia research. Among the many research agendas, multicenter harmonization of neuroscientific measures, the exploration of alternative dementia biomarkers using neuroimaging and EEG, the use of machine learning to combine data from sensitive cognitive tasks with multimodal neuroimaging across different neurodegenerative conditions, and the basic neuroscience of genetic presentations and therapeutics are hot topics for future research amplification in the region.

\section{ACKNOWLEDGMENTS}

Agustin Ibanez is partially supported by grants from Alzheimer's Association GBHI ALZ UK-20639295, Takeda CW2680521, CONICET, ANID/ FONDAP/15150012, The Inter-American Development Bank (IDB), Sistema General de Regalías [BPIN2018000100059], Universidad del Valle [CI 5316], and the MULTI-PARTNER CONSORTIUM TO EXPAND DEMENTIA RESEARCH IN LATIN AMERICA [ReDLat, supported by National Institutes of Health, National Institutes of Aging (R01 AG057234), Alzheimer's Association (SG-20725707), Rainwater Charitable foundation - Tau Consortium, and Global Brain Health Institute]. Mario A Parra work is supported by a MRC grant (MRC-R42552) and two Alzheimer's Society Grants (AS-R42303 and AS-SF-14-008). Christopher Butler is supported by the Medical Research Council (MR/K010395/1). The contents of this publication are solely the responsibility of the authors and do not represent the official views of these institutions.

Authors' disclosures available online (https:// www.j-alz.com/manuscript-disclosures/20-1384r1).

\section{REFERENCES}

[1] Parra MA, Baez S, Sedeño L, Gonzalez Campo C, Santamaría-García H, Aprahamian I, Bertolucci PHF, Bustin J, Bicalho MAC, Cano-Gutierrez C, et al. (2020) Dementia in Latin America: Paving the way towards a regional action plan. Alzheimers Dement, doi: 10.1002/alz.12202

[2] Parra MA, Baez S, Allegri R, Nitrini R, Lopera F, Slachevsky A, Custodio N, Lira D, Piguet O, Kumfor F, Huepe D, Cogram P, Bak T, Manes F, Ibanez A (2018) Dementia in Latin America: Assessing the present and envisioning the future. Neurology 90, 222-231.

[3] (2014) Addressing global dementia. Lancet 383, 2185.

[4] Alladi S, Hachinski V (2018) World dementia: One approach does not fit all. Neurology 91, 264-270.

[5] Dartigues JF (2009) Alzheimer's disease: A global challenge for the 21st century. Lancet Neurol 8, 1082-1083.

[6] Shah H, Albanese E, Duggan C, Rudan I, Langa KM, Carrillo MC, Chan KY, Joanette Y, Prince M, Rossor M, Saxena S, Snyder HM, Sperling R, Varghese M, Wang H, Wortmann M, Dua T (2016) Research priorities to reduce the global burden of dementia by 2025. Lancet Neurol 15, 1285-1294.

[7] Wu YT, Beiser AS, Breteler MMB, Fratiglioni L, Helmer C, Hendrie HC, Honda H, Ikram MA, Langa KM, Lobo A, Matthews FE, Ohara T, Peres K, Qiu C, Seshadri S, Sjolund BM, Skoog I, Brayne C (2017) The changing prevalence and incidence of dementia over time - current evidence. Nat Rev Neurol 13, 327-339.

[8] Aguirre-Acevedo DC, Lopera F, Henao E, Tirado V, Munoz C, Giraldo M, Bangdiwala SI, Reiman EM, Tariot PN, Langbaum JB, Quiroz YT, Jaimes F (2016) Cognitive decline in a colombian kindred with autosomal dominant 
Alzheimer disease: A retrospective cohort study. JAMA Neurol 73, 431-438.

[9] Baez S, Ibanez A (2016) Dementia in Latin America: An emergent silent tsunami. Front Aging Neurosci 8, 253.

[10] Reitz C, Mayeux R (2014) Genetics of Alzheimer's disease in Caribbean Hispanic and African American populations. Biol Psychiatry 75, 534-541.

[11] Tosto G, Bird TD, Tsuang D, Bennett DA, Boeve BF, Cruchaga C, Faber K, Foroud TM, Farlow M, Goate AM, Bertlesen S, Graff-Radford NR, Medrano M, Lantigua R, Manly J, Ottman R, Rosenberg R, Schaid DJ, Schupf N, Stern Y, Sweet RA, Mayeux R (2017) Polygenic risk scores in familial Alzheimer disease. Neurology 88, 11801186.

[12] Kalaria RN, Maestre GE, Arizaga R, Friedland RP, Galasko D, Hall K, Luchsinger JA, Ogunniyi A, Perry EK, Potocnik F, Prince M, Stewart R, Wimo A, Zhang ZX, Antuono P, World Federation of Neurology Dementia Research Group (2008) Alzheimer's disease and vascular dementia in developing countries: Prevalence, management, and risk factors. Lancet Neurol 7, 812-826.

[13] World Health Organization International, Alzheimer's Disease International (2012) Dementia: A Public Health Priority. World Health Organization

[14] Livingston G, Huntley J, Sommerlad A, Ames D, Ballard C, Banerjee S, Brayne C, Burns A, Cohen-Mansfield J, Cooper C, Costafreda SG, Dias A, Fox N, Gitlin LN, Howard R, Kales HC, Kivimäki M, Larson EB, Ogunniyi A, Orgeta V, Ritchie K, Rockwood K, Sampson EL, Samus Q, Schneider LS, Selbæk G, Teri L, Mukadam N (2020) Dementia prevention, intervention, and care: 2020 report of the Lancet Commission. Lancet 396, 413-446.

[15] Mukadam N, Sommerlad A, Huntley J, Livingston G (2019) Population attributable fractions for risk factors for dementia in low-income and middle-income countries: An analysis using cross-sectional survey data. Lancet Glob Health 7, e596-e603.

[16] Parra MA (2014) Overcoming barriers in cognitive assessment of Alzheimer's disease. Dement Neuropsychol 8, 95-98.

[17] Custodio N, Wheelock A, Thumala D, Slachevsky A (2017) Dementia in Latin America: Epidemiological evidence and implications for public policy. Front Aging Neurosci 9, 221.

[18] Ibáñez A, Sedeño L, García AM, Deacon RMJ, Cogram P (2018) Editorial: Human and animal models for translational research on neurodegeneration: Challenges and opportunities from South America. Front Aging Neurosci 10,95 .

[19] Ramos C, Aguillon D, Cordano C, Lopera F (2020) Genetics of dementia: Insights from Latin America. Dement Neuropsychol 14, 223-236.

[20] Bachli MB, Sedeno L, Ochab JK, Piguet O, Kumfor F, Reyes P, Torralva T, Roca M, Cardona JF, Campo CG, Herrera E, Slachevsky A, Matallana D, Manes F, Garcia AM, Ibanez A, Chialvo DR (2020) Evaluating the reliability of neurocognitive biomarkers of neurodegenerative diseases across countries: A machine learning approach. Neuroimage 208, 116456.

[21] Abrevaya S, Fittipaldi S, Garcia AM, Dottori M, Santamaria-Garcia H, Birba A, Yoris A, Hildebrandt MK, Salamone P, De la Fuente A, Alarco-Marti S, GarciaCordero I, Matorrel-Caro M, Pautassi RM, Serrano C, Sedeno L, Ibanez A (2020) At the heart of neurological dimensionality: Cross-nosological and multimodal cardiac interoceptive deficits. Psychosom Med 82, 850-861.

[22] Garcia-Cordero I, Sedeno L, Babino A, Dottori M, Melloni M, Martorell Caro M, Sigman M, Herrera E, Manes F, Garcia AM, Ibanez A (2019) Explicit and implicit monitoring in neurodegeneration and stroke. Sci Rep 9, 14032.

[23] Fittipaldi S, Ibanez A, Baez S, Manes F, Sedeno L, Garcia AM (2019) More than words: Social cognition across variants of primary progressive aphasia. Neurosci Biobehav Rev 100, 263-284.

[24] Donnelly-Kehoe PA, Pascariello GO, Garcia AM, Hodges JR, Miller B, Rosen H, Manes F, Landin-Romero R, Matallana D, Serrano C, Herrera E, Reyes P, Santamaria-Garcia H, Kumfor F, Piguet O, Ibanez A, Sedeno L (2019) Robust automated computational approach for classifying frontotemporal neurodegeneration: Multimodal/multicenter neuroimaging. Alzheimers Dement (Amst) 11, 588-598.

[25] Moguilner S, Garcia AM, Mikulan E, Hesse E, GarciaCordero I, Melloni M, Cervetto S, Serrano C, Herrera E, Reyes P, Matallana D, Manes F, Ibanez A, Sedeno L (2018) Weighted symbolic dependence metric (wSDM) for fMRI resting-state connectivity: A multicentric validation for frontotemporal dementia. Sci Rep 8, 11181.

[26] Baez S, Pino M, Berrio M, Santamaria-Garcia H, Sedeno L, Garcia AM, Fittipaldi S, Ibanez A (2018) Corticostriatal signatures of schadenfreude: Evidence from Huntington's disease. J Neurol Neurosurg Psychiatry 89, 112-116.

[27] Sedeno L, Piguet O, Abrevaya S, Desmaras H, GarciaCordero I, Baez S, Alethia de la Fuente L, Reyes P, Tu S, Moguilner S, Lori N, Landin-Romero R, Matallana D, Slachevsky A, Torralva T, Chialvo D, Kumfor F, Garcia AM, Manes F, Hodges JR, Ibanez A (2017) Tackling variability: A multicenter study to provide a goldstandard network approach for frontotemporal dementia. Hum Brain Mapp 38, 3804-3822.

[28] Parra MA, Mikulan E, Trujillo N, Sala SD, Lopera F, Manes F, Starr J, Ibanez A (2017) Brain information sharing during visual short-term memory binding yields a memory biomarker for familial Alzheimer's disease. Curr Alzheimer Res 14, 1335-1347.

[29] Dottori M, Sedeno L, Martorell Caro M, Alifano F, Hesse E, Mikulan E, Garcia AM, Ruiz-Tagle A, Lillo P, Slachevsky A, Serrano C, Fraiman D, Ibanez A (2017) Towards affordable biomarkers of frontotemporal dementia: A classification study via network's information sharing. Sci Rep 7, 3822.

[30] Birba A, Garcia-Cordero I, Kozono G, Legaz A, Ibanez A, Sedeno L, Garcia AM (2017) Losing ground: Frontostriatal atrophy disrupts language embodiment in Parkinson's and Huntington's disease. Neurosci Biobehav Rev 80, 673-687.

[31] Sedeno L, Couto B, Garcia-Cordero I, Melloni M, Baez S, Morales Sepulveda JP, Fraiman D, Huepe D, Hurtado E, Matallana D, Kuljis R, Torralva T, Chialvo D, Sigman M, Piguet O, Manes F, Ibanez A (2016) Brain network organization and social executive performance in frontotemporal dementia. J Int Neuropsychol Soc 22, 250-262.

[32] Santamaria-Garcia H, Reyes P, Garcia A, Baez S, Martinez A, Santacruz JM, Slachevsky A, Sigman M, Matallana D, Ibanez A (2016) First symptoms and neurocognitive correlates of behavioral variant frontotemporal dementia. J Alzheimers Dis 54, 957-970.

[33] Garcia-Cordero I, Sedeno L, Fraiman D, Craiem D, de la Fuente LA, Salamone P, Serrano C, Sposato L, Manes F, Ibanez A (2015) Stroke and neurodegeneration induce 
different connectivity aberrations in the insula. Stroke $\mathbf{4 6}$, 2673-2677.

[34] Baez S, Manes F, Huepe D, Torralva T, Fiorentino N, Richter F, Huepe-Artigas D, Ferrari J, Montanes P, Reyes P, Matallana D, Vigliecca NS, Decety J, Ibanez A (2014) Primary empathy deficits in frontotemporal dementia. Front Aging Neurosci 6, 262.

[35] Baez S, Couto B, Torralva T, Sposato LA, Huepe D, Montanes P, Reyes P, Matallana D, Vigliecca NS, Slachevsky A, Manes F, Ibanez A (2014) Comparing moral judgments of patients with frontotemporal dementia and frontal stroke. JAMA Neurol 71, 1172-1176.

[36] Parra MA, Saarimaki H, Bastin ME, Londono AC, Pettit L, Lopera F, Della Sala S, Abrahams S (2015) Memory binding and white matter integrity in familial Alzheimer's disease. Brain 138, 1355-1369.

[37] Parra MA, Abrahams S, Logie RH, Mendez LG, Lopera F, Della Sala S (2010) Visual short-term memory binding deficits in familial Alzheimer's disease. Brain 133, 27022713.

[38] Parra MA, Abrahams S, Fabi K, Logie R, Luzzi S, Della Sala S (2009) Short-term memory binding deficits in Alzheimer's disease. Brain 132, 1057-1066.

[39] Prince M, Brodaty H, Uwakwe R, Acosta D, Ferri CP, Guerra M, Huang Y, Jacob KS, Llibre Rodriguez JJ, Salas A, Sosa AL, Williams JD, Jotheeswaran AT, Liu Z (2012) Strain and its correlates among carers of people with dementia in low-income and middle-income countries. A 10/66 Dementia Research Group population-based survey. Int J Geriatr Psychiatry 27, 670-682.

[40] Morlett Paredes A, Perrin PB, Peralta SV, Stolfi ME, Morelli E, Arango-Lasprilla JC (2017) Structural equation model linking dementia cognitive functioning, caregiver mental health, burden, and quality of informal care in Argentina. Dementia (London) 16, 766-779.

[41] Ferretti C, Sarti FM, Nitrini R, Ferreira FF, Brucki SMD (2018) An assessment of direct and indirect costs of dementia in Brazil. PLoS One 13, e0193209.

[42] Hojman DA, Duarte F, Ruiz-Tagle J, Budnich M, Delgado C, Slachevsky A (2017) The cost of dementia in an unequal country: The case of Chile. PLoS One 12, e0172204.

[43] Moreno JA, Nicholls E, Ojeda N, De los Reyes-Aragon CJ, Rivera D, Arango-Lasprilla JC (2015) Caregiving in dementia and its impact on psychological functioning and health-related quality of life: Findings from a Colombian sample. J Cross Cult Gerontol 30, 393-408.

[44] Lloyd-Sherlock P, Mayston R, Acosta A, Gallardo S, Guerra M, Sosa AL, Montes de Oca V, Prince M (2017) Allocating family responsibilities for dependent older people in Mexico and Peru. J Dev Stud 54, 682-701.

[45] Custodio N, Lira D, Herrera-Perez E, Del Prado LN, Parodi J, Guevara-Silva E, Castro-Suarez S, Mar M, Montesinos R, Cortijo P (2014) Informal caregiver burden in middle-income countries: Results from Memory Centers in Lima - Peru. Dement Neuropsychol 8, 376-383.

[46] Matus-Lopez M, Pedraza CC (2016) New long-term care policies in Latin America: The national system of care in Uruguay. J Am Med Dir Assoc 17, 663-665.

[47] Rossini PM, Di Iorio R, Vecchio F, Anfossi M, Babiloni C, Bozzali M, Bruni AC, Cappa SF, Escudero J, Fraga FJ, Giannakopoulos P, Guntekin B, Logroscino G, Marra C, Miraglia F, Panza F, Tecchio F, Pascual-Leone A, Dubois B (2020) Early diagnosis of Alzheimer's disease: The role of biomarkers including advanced EEG signal analysis.
Report from the IFCN-sponsored panel of experts. Clin Neurophysiol 131, 1287-1310.

[48] McMackin R, Muthuraman M, Groppa S, Babiloni C, Taylor JP, Kiernan MC, Nasseroleslami B, Hardiman O (2019) Measuring network disruption in neurodegenerative diseases: New approaches using signal analysis. J Neurol Neurosurg Psychiatry 90, 1011-1020.

[49] Hampel H, Toschi N, Babiloni C, Baldacci F, Black KL, Bokde ALW, Bun RS, Cacciola F, Cavedo E, Chiesa PA, Colliot O, Coman CM, Dubois B, Duggento A, Durrleman S, Ferretti MT, George N, Genthon R, Habert MO, Herholz K, Koronyo Y, Koronyo-Hamaoui M, Lamari F, Langevin T, Lehericy S, Lorenceau J, Neri C, Nistico R, NyasseMessene F, Ritchie C, Rossi S, Santarnecchi E, Sporns O, Verdooner SR, Vergallo A, Villain N, Younesi E, Garaci F, Lista S, Alzheimer Precision Medicine I (2018) Revolution of Alzheimer precision neurology. Passageway of systems biology and neurophysiology. J Alzheimers Dis 64, S47-S105.

[50] Yoris A, Abrevaya S, Esteves S, Salamone P, Lori N, Martorell M, Legaz A, Alifano F, Petroni A, Sanchez R, Sedeno L, Garcia AM, Ibanez A (2018) Multilevel convergence of interoceptive impairments in hypertension: New evidence of disrupted body-brain interactions. Hum Brain Mapp 39, 1563-1581.

[51] Garcia-Cordero I, Esteves S, Mikulan EP, Hesse E, Baglivo FH, Silva W, Garcia MDC, Vaucheret E, Ciraolo C, Garcia HS, Adolfi F, Pietto M, Herrera E, Legaz A, Manes F, Garcia AM, Sigman M, Bekinschtein TA, Ibanez A, Sedeno L (2017) Attention, in and out: Scalp-level and intracranial EEG correlates of interoception and exteroception. Front Neurosci 11, 411.

[52] Amoruso L, Ibanez A, Fonseca B, Gadea S, Sedeno L, Sigman M, Garcia AM, Fraiman R, Fraiman D (2017) Variability in functional brain networks predicts expertise during action observation. Neuroimage 146, 690-700.

[53] Pietto M, Parra MA, Trujillo N, Flores F, Garcia AM, Bustin J, Richly P, Manes F, Lopera F, Ibanez A, Baez S (2016) Behavioral and electrophysiological correlates of memory binding deficits in patients at different risk levels for Alzheimer's disease. J Alzheimers Dis 53, 13251340.

[54] Gonzalez-Gadea ML, Sigman M, Rattazzi A, Lavin C, Rivera-Rei A, Marino J, Manes F, Ibanez A (2016) Neural markers of social and monetary rewards in children with attention-deficit/hyperactivity disorder and autism spectrum disorder. Sci Rep 6, 30588.

[55] Gonzalez-Gadea ML, Chennu S, Bekinschtein TA, Rattazzi A, Beraudi A, Tripicchio P, Moyano B, Soffita Y, Steinberg L, Adolfi F, Sigman M, Marino J, Manes F, Ibanez A (2015) Predictive coding in autism spectrum disorder and attention deficit hyperactivity disorder. $\mathrm{J} \mathrm{Neu}$ rophysiol 114, 2625-2636.

[56] Couto B, Adolfi F, Velasquez M, Mesow M, Feinstein J, Canales-Johnson A, Mikulan E, Martinez-Pernia D, Bekinschtein T, Sigman M, Manes F, Ibanez A (2015) Heart evoked potential triggers brain responses to natural affective scenes: A preliminary study. Auton Neurosci 193, 132-137.

[57] Canales-Johnson A, Silva C, Huepe D, Rivera-Rei A, Noreika V, Garcia Mdel C, Silva W, Ciraolo C, Vaucheret E, Sedeno L, Couto B, Kargieman L, Baglivo F, Sigman M, Chennu S, Ibanez A, Rodriguez E, Bekinschtein TA (2015) Auditory feedback differentially modulates behavioral and neural markers of objective and subjective performance 
when tapping to your heartbeat. Cereb Cortex 25, 44904503.

[58] Ibanez A, Aguado J, Baez S, Huepe D, Lopez V, Ortega R, Sigman M, Mikulan E, Lischinsky A, Torrente F, Cetkovich M, Torralva T, Bekinschtein T, Manes F (2014) From neural signatures of emotional modulation to social cognition: Individual differences in healthy volunteers and psychiatric participants. Soc Cogn Affect Neurosci $\mathbf{9}$, 939-950.

[59] Escobar MJ, Huepe D, Decety J, Sedeno L, Messow MK, Baez S, Rivera-Rei A, Canales-Johnson A, Morales JP, Gomez DM, Schroeder J, Manes F, Lopez V, Ibanez A (2014) Brain signatures of moral sensitivity in adolescents with early social deprivation. Sci Rep 4, 5354.

[60] Barttfeld P, Petroni A, Baez S, Urquina H, Sigman M, Cetkovich M, Torralva T, Torrente F, Lischinsky A, Castellanos X, Manes F, Ibanez A (2014) Functional connectivity and temporal variability of brain connections in adults with attention deficit/hyperactivity disorder and bipolar disorder. Neuropsychobiology 69, 65-75.

[61] Amoruso L, Sedeno L, Huepe D, Tomio A, Kamienkowski J, Hurtado E, Cardona JF, Alvarez Gonzalez MA, Rieznik A, Sigman M, Manes F, Ibanez A (2014) Time to Tango: Expertise and contextual anticipation during action observation. Neuroimage 98, 366-385.

[62] Ibanez A, Cardona JF, Dos Santos YV, Blenkmann A, Aravena P, Roca M, Hurtado E, Nerguizian M, Amoruso L, Gomez-Arevalo G, Chade A, Dubrovsky A, Gershanik O, Kochen S, Glenberg A, Manes F, Bekinschtein T (2013) Motor-language coupling: Direct evidence from early Parkinson's disease and intracranial cortical recordings. Cortex 49, 968-984.

[63] Escobar MJ, Rivera-Rei A, Decety J, Huepe D, Cardona JF, Canales-Johnson A, Sigman M, Mikulan E, Helgiu E, Baez S, Manes F, Lopez V, Ibanez A (2013) Attachment patterns trigger differential neural signature of emotional processing in adolescents. PLoS One 8, e70247.

[64] Chennu S, Noreika V, Gueorguiev D, Blenkmann A, Kochen S, Ibanez A, Owen AM, Bekinschtein TA (2013) Expectation and attention in hierarchical auditory prediction. J Neurosci 33, 11194-11205.

[65] Barttfeld P, Amoruso L, Ais J, Cukier S, Bavassi L, Tomio A, Manes F, Ibanez A, Sigman M (2013) Organization of brain networks governed by long-range connections index autistic traits in the general population. J Neurodev Disord $5,16$.

[66] Ibanez A, Riveros R, Hurtado E, Gleichgerrcht E, Urquina H, Herrera E, Amoruso L, Reyes MM, Manes F (2012) The face and its emotion: Right N170 deficits in structural processing and early emotional discrimination in schizophrenic patients and relatives. Psychiatry Res 195, 18-26.

[67] Petroni A, Canales-Johnson A, Urquina H, Guex R, Hurtado E, Blenkmann A, von Ellenrieder N, Manes F, Sigman M, Ibanez A (2011) The cortical processing of facial emotional expression is associated with social cognition skills and executive functioning: A preliminary study. Neurosci Lett 505, 41-46.

[68] Ibanez A, Toro P, Cornejo C, Urquina H, Manes F, Weisbrod M, Schroder J (2011) High contextual sensitivity of metaphorical expressions and gesture blending: A video event-related potential design. Psychiatry Res 191, 68-75.

[69] Ibanez A, Riveros R, Aravena P, Vergara V, Cardona JF, Garcia L, Hurtado E, Reyes MM, Barutta J, Manes F (2011) When context is difficult to integrate: Cortical measures of congruency in schizophrenics and healthy relatives from multiplex families. Schizophr Res $\mathbf{1 2 6}$, 303-305.

[70] Ibanez A, Petroni A, Urquina H, Torrente F, Torralva T, Hurtado E, Guex R, Blenkmann A, Beltrachini L, Muravchik C, Baez S, Cetkovich M, Sigman M, Lischinsky A, Manes F (2011) Cortical deficits of emotional face processing in adults with ADHD: Its relation to social cognition and executive function. Soc Neurosci $\mathbf{6}$, 464-481.

[71] Dufey M, Hurtado E, Fernandez AM, Manes F, Ibanez A (2011) Exploring the relationship between vagal tone and event-related potentials in response to an affective picture task. Soc Neurosci 6, 48-62.

[72] Aravena P, Hurtado E, Riveros R, Cardona JF, Manes F, Ibanez A (2010) Applauding with closed hands: Neural signature of action-sentence compatibility effects. PLoS One 5, e11751.

[73] Hurtado E, Haye A, Gonzalez R, Manes F, Ibanez A (2009) Contextual blending of ingroup/outgroup face stimuli and word valence: LPP modulation and convergence of measures. BMC Neurosci 10, 69.

[74] Guerra S, Ibanez A, Martin M, Bobes MA, Reyes A, Mendoza R, Bravo T, Dominguez M, Sosa MV (2009) N400 deficits from semantic matching of pictures in probands and first-degree relatives from multiplex schizophrenia families. Brain Cogn 70, 221-230.

[75] Cornejo C, Simonetti F, Ibanez A, Aldunate N, Ceric F, Lopez V, Nunez RE (2009) Gesture and metaphor comprehension: Electrophysiological evidence of cross-modal coordination by audiovisual stimulation. Brain Cogn 70, 42-52.

[76] Melloni M, Billeke P, Baez S, Hesse E, de la Fuente L, Forno G, Birba A, Garcia-Cordero I, Serrano C, Plastino A, Slachevsky A, Huepe D, Sigman M, Manes F, Garcia AM, Sedeno L, Ibanez A (2016) Your perspective and my benefit: Multiple lesion models of self-other integration strategies during social bargaining. Brain 139, 3022-3040.

[77] García-Cordero I, Sedeño L, de la Fuente L, Slachevsky A, Forno G, Klein F, Lillo P, Ferrari J, Rodriguez C, Bustin J, Torralva T, Baez S, Yoris A, Esteves S, Melloni M, Salamone P, Huepe D, Manes F, García A, Ibañez A (2016) Feeling, learning from, and being aware of inner states: Interoceptive dimensions in neurodegeneration and stroke. Philos Trans R Soc Lond B Biol Sci 371, 20160006.

[78] Hesse E, Mikulan E, Decety J, Sigman M, Garcia Mdel C, Silva W, Ciraolo C, Vaucheret E, Baglivo F, Huepe D, Lopez V, Manes F, Bekinschtein TA, Ibanez A (2016) Early detection of intentional harm in the human amygdala. Brain 139, 54-61.

[79] Hesse E, Mikulan E, Sitt JD, Garcia MDC, Silva W, Ciraolo C, Vaucheret E, Raimondo F, Baglivo F, Adolfi F, Herrera E, Bekinschtein TA, Petroni A, Lew S, Sedeno L, Garcia AM, Ibanez A (2019) Consistent gradient of performance and decoding of stimulus type and valence from local and network activity. IEEE Trans Neural Syst Rehabil Eng 27, 619-629.

[80] Mikulan E, Hesse E, Sedeño L, Bekinschtein T, Sigman M, García MDC, Silva W, Ciraolo C, García AM, Ibáñez A (2018) Intracranial high- $\gamma$ connectivity distinguishes wakefulness from sleep. Neuroimage 169, 265-277.

[81] Garcia AM, Hesse E, Birba A, Adolfi F, Mikulan E, Caro MM, Petroni A, Bekinschtein TA, Del Carmen Garcia M, Silva W, Ciraolo C, Vaucheret E, Sedeno L, Ibanez A (2020) Time to face language: Embodied mechanisms 
underpin the inception of face-related meanings in the human brain. Cereb Cortex 30, 6051-6068.

[82] Birba A, Beltran D, Martorell Caro M, Trevisan P, Kogan B, Sedeno L, Ibanez A, Garcia AM (2020) Motor-system dynamics during naturalistic reading of action narratives in first and second language. Neuroimage 216, 116820.

[83] Josefsson A, Ibanez A, Parra M, Escudero J (2019) Network analysis through the use of joint-distribution entropy on EEG recordings of MCI patients during a visual short-term memory binding task. Healthc Technol Lett $\mathbf{6}$, 27-31.

[84] Ibanez A, Billeke P, de la Fuente L, Salamone P, Garcia AM, Melloni M (2017) Reply: Towards a neurocomputational account of social dysfunction in neurodegenerative disease. Brain 140, e15.

[85] Ibanez A (2018) Brain oscillations, inhibition and social inappropriateness in frontotemporal degeneration. Brain 141, e73.

[86] Melloni M, Sedeno L, Hesse E, Garcia-Cordero I, Mikulan E, Plastino A, Marcotti A, Lopez JD, Bustamante C, Lopera F, Pineda D, Garcia AM, Manes F, Trujillo N, Ibanez A (2015) Cortical dynamics and subcortical signatures of motor-language coupling in Parkinson's disease. Sci Rep 5, 11899.

[87] Fittipaldi S, Abrevaya S, Fuente A, Pascariello GO, Hesse E, Birba A, Salamone P, Hildebrandt M, Marti SA, Pautassi RM, Huepe D, Martorell MM, Yoris A, Roca M, Garcia AM, Sedeno L, Ibanez A (2020) A multidimensional and multi-feature framework for cardiac interoception. $\mathrm{Neu}$ roimage 212, 116677.

[88] Salamone PC, Esteves S, Sinay VJ, Garcia-Cordero I, Abrevaya S, Couto B, Adolfi F, Martorell M, Petroni A, Yoris A, Torquati K, Alifano F, Legaz A, Cassara FP, Bruno D, Kemp AH, Herrera E, Garcia AM, Ibanez A, Sedeno L (2018) Altered neural signatures of interoception in multiple sclerosis. Hum Brain Mapp 39, 4743-4754.

[89] Moguilner S, García AM, Perl YS, Tagliazucchi E, Piguet O, Kumfor F, Reyes P, Matallana D, Sedeño L, Ibáñez A (2020) Dynamic brain fluctuations outperform connectivity measures and mirror pathophysiological profiles across dementia subtypes: A multicenter study. Neuroimage 225, 117522.

[90] Jack CR, Jr., Bennett DA, Blennow K, Carrillo MC, Dunn B, Haeberlein SB, Holtzman DM, Jagust W, Jessen F, Karlawish J, Liu E, Molinuevo JL, Montine T, Phelps C, Rankin KP, Rowe CC, Scheltens P, Siemers E, Snyder HM, Sperling R, Contributors (2018) NIA-AA Research Framework: Toward a biological definition of Alzheimer's disease. Alzheimers Dement 14, 535-562.

[91] Ibanez A, Parra MA (2014) Mapping memory binding onto the connectome's temporal dynamics: Toward a combined biomarker for Alzheimer's disease. Front Hum Neurosci 8, 237.

[92] Musa G, Slachevsky A, Munoz-Neira C, Mendez-Orellana C, Villagra R, Gonzalez-Billault C, Ibanez A, Hornberger M, Lillo P (2020) Alzheimer's disease or behavioral variant frontotemporal dementia? Review of key points toward an accurate clinical and neuropsychological diagnosis. $J$ Alzheimers Dis 73, 833-848.

[93] (2020) New manual aims to create common standards for dementia diagnosis across Latin America. Alzheimers Dement 16, 1099.

[94] Ibanez A, Kosik KS, Latin A, the Caribbean Consortium on D (2020) COVID-19 in older people with cognitive impairment in Latin America. Lancet Neurol 19, 719-721.
[95] Dawson WD, Bobrow K, Ibanez A, Booi L, Pintado-Caipa M, Yamamoto S, Tarnanas I, Evans T, Comas-Herrera A, Cummings J, Kaye J, Yaffe K, Miller BL, Eyre HA (2020) The necessity of diplomacy in brain health. Lancet Neurol 19, 972-974.

[96] Smith E, Ali D, Wilkerson B, Dawson WD, Sobowale K, Reynolds C, 3rd, Berk M, Lavretsky H, Jeste D, Ng CH, Soares JC, Aragam G, Wainer Z, Manji HK, Licinio J, Lo AW, Storch E, Fu E, Leboyer M, Tarnanas I, Ibanez A, Manes F, Caddick S, Fillit H, Abbott R, Robertson IH, Chapman SB, Au R, Altimus CM, Hynes W, Brannelly P, Cummings J, Eyre HA (2020) A Brain Capital Grand Strategy: Toward economic reimagination. Mol Psychiatry, 10.1038/s41380-41020-00918-w.

[97] Ternes K, Iyengar V, Lavretsky H, Dawson WD, Booi L, Ibanez A, Vahia I, Reynolds C, DeKosky S, Cummings J, Miller B, Perissinotto C, Kaye J, Eyre HA (2020) Brain health INnovation Diplomacy: A model binding diverse disciplines to manage the promise and perils of technological innovation. Int Psychogeriatr 32, 955-979.

[98] Ibanez A, Santamaria-Garcia H, Guerrero Barragan A, Kornhuber A, Ton AMM, Slachevsky A, Teixeira AL, Mar Meza BM, Serrano CM, Cano C, Arias Gonzalez C, Gonzalez-Billault C, Butler C, Bustin J, Duran-Aniotz C, Acosta D, Matallana DL, Acosta-Alvear D, Trépel D, Resende EPF, de Oliveira FF, Ibanez F, De Felice FG, Navarrete G, Tarnanas I, Meier IB, Smid J, Llibre-Guerra J, Llibre-Rodriguez JJ, Fajersztajn L, Takada LT, Duque L, Okada de Oliveira M, Bicalho MAC, Behrens MI, PintadoCaipa M, Parra M, Wilson MZ, De La Cruz Puebla M, Custodio N, Santibanez R, Serafim RB, Tavares RM, Piña Escudero SD, Leon Rodriguez T, Dawson W, Miller BL, Kosik KS (2020) The impact of SARS-CoV-2 in dementia across Latin America: A call for an urgent regional plan and coordinated response. Alzheimers Dement (N Y) 6, e12092.

[99] Ibanez A, Flichtentrei D, Hesse E, Dottori M, Tomio A, Slachevsky A, Serrano CM, Gonzalez-Billaut C, Custodio N, Miranda C, Bustin J, Cetckovitch M, Torrente F, Olavarria L, Leon T, Beber BC, Bruki S, Suemoto CK, Nitrini R, Miller BL, Yokoyama JS (2020) The power of knowledge about dementia in Latin America across health professionals working on aging. Alzheimers Dement (Amst) 12, e12117.

[100] Custodio N, Montesinos R, Lira D, Herrera-Perez E, Chavez K, Reynoso-Guzman W, Pintado-Caipa M, Cuenca J, Gamboa C, Metcalf T (2020) Validation of the RUDAS for the Identification of Dementia in Illiterate and Low-Educated Older Adults in Lima, Peru. Front Neurol 11, 374.

[101] Custodio N, Montesinos R, Lira D, Herrera-Perez E, Chavez K, Hernandez-Cordova G, Cuenca J, Gamboa C, Metcalf T (2019) Validation of the RUDAS in patients with a middle-level education in Lima, Peru. Am J Alzheimers Dis Other Demen 34, 513-522.

[102] Custodio N, Lira D, Herrera-Perez E, Montesinos R, Castro-Suarez S, Cuenca-Alfaro J, Valeriano-Lorenzo L (2017) Memory alteration test to detect amnestic mild cognitive impairment and early Alzheimer's dementia in population with low educational level. Front Aging $\mathrm{Neu}$ rosci $9,278$.

[103] Graham ID, Logan J, Harrison MB, Straus SE, Tetroe J, Caswell W, Robinson N (2006) Lost in knowledge translation: Time for a map? J Contin Educ Health Prof 26, 13-24. 
[104] Gonzalez Campo C, Salamone PC, Rodriguez-Arriagada N, Richter F, Herrera E, Bruno D, Pagani Cassara F, Sinay V, Garcia AM, Ibanez A, Sedeno L (2020) Fatigue in multiple sclerosis is associated with multimodal interoceptive abnormalities. Mult Scler 26, 1845-1853.

[105] Santamaria-Garcia H, Baez S, Reyes P, Santamaria-Garcia JA, Santacruz-Escudero JM, Matallana D, Arevalo A,
Sigman M, Garcia AM, Ibanez A (2017) A lesion model of envy and Schadenfreude: Legal, deservingness and moral dimensions as revealed by neurodegeneration. Brain 140, 3357-3377. 